\title{
Amós 7,1-6: Amós não pede por justiça, mas por misericórdia
}

\author{
Amos 7,1-6: Amos does not ask for justice, but for mercy
}

\section{Amos 7,1-6: Amós no pide justicia, sino por misericordia}

\author{
José Jacinto de Ribamar Mendes Filho*
}

\begin{abstract}
RESUMO
Este trabalho se propõe a estudar a passagem de Amós 7,1-6, buscando entender o que está implicado teologicamente no primeiro par de visões, respondendo o que levou Deus a se arrepender. $O$ trabalho está dividido em três seções: a primeira seção busca analisar a visão dos gafanhotos e do fogo, considerando que elas apontam para um juízo de Deus sobre um povo fraco e pequeno. Das informações obtidas nesta primeira parte, buscar-se-á interligá-las à segunda parte (apelo em favor de um povo fraco e pequeno), focalizando a ideia de um apelo em favor do povo de Israel, buscando entender as primeiras implicações teológicas a respeito do juízo de Deus como "o dia de Javé". Este dia de Javé, tanto positivo quanto negativo para o povo de Deus, só poderá ser impedido se houver uma intercessão em favor do povo. Palavras-chave: Visão; apelo; arrependimento; misericórdia.
\end{abstract}

\begin{abstract}
This work proposes to study the passage of Amos 7.1-6, seeking to understand what is theologically implicated in the first pair of visions, answering what led God to repent. The work is divided into three sections: the first section seeks to analyze the vision of the locusts and the fire, considering that they point to a judgment of God on a weak and small people. From the information obtained in this first part, it will be sought to interconnect them with the second part (appeal for a weak and small people), focusing on the idea of an appeal for the people of Israel, seeking to understand the first theological implications to respect of God's judgment as "the day of the Lord". This day of Yahweh, both positive and negative for the people of God, can only be prevented if there is an intercession on behalf of the people.

Keywords: Vision; appeal; repentance; mercy.

RESUMEN

Este trabajo se propone a estudiar el pasaje de Amós 7.1-6, buscando entender lo que está implicado teologicamente en el primer par de visiones, respondiendo lo que llevó a Dios a arrepentirse. El trabajo está dividido en tres secciones: la primera sección busca analizar la visión de las langostas y del fuego, considerando que ellas apuntan a un juicio de Dios sobre un pueblo débil y pequeño. De las informaciones obtenidas en esta primera parte, se buscará interconectarlas a la segunda parte (llamamiento a favor de un pueblo débil y pequeño), enfocando la idea de un llamamiento en favor del pueblo de Israel, buscando entender las primeras implicaciones teológicas a el respeto del juicio de Dios como "el día de Yahvé". Este día de Yahvé, tanto positivo como negativo para el pueblo de Dios, sólo podrá ser impedido si hay una intercesión en favor del pueblo.

Palabras clave: Visión; apelo; arrepentimiento; misericórdia.
\end{abstract}

\footnotetext{
* Mestre em Teologia pelas Faculdades EST em São Leopoldo, RS, Brasil. Pesquisador associado à Fundação de Amparo à Pesquisa do Estado do Amazonas (FAPEAM). E-mail: jacintodefilho@hotmail.com
} 


\section{Introdução}

O texto abordará o contexto em que ocorrem as duas primeiras visões de Amós 7. ${ }^{1}$ O primeiro par de visões, dos gafanhotos e do fogo, explica o terrível dia que sobrevirá às cidades, principalmente às cidade de Israel e Judá (sobre o povo de Deus). Mas, em reações de desespero, o profeta Amós, em favor do povo fraco e pequeno, pede perdão a Javé. Deus terá compaixão deste povo? Para obter a resposta desta pergunta será preciso analisar paralelamente outras passagens, procurando entender o que levou Deus a se arrepender.

Para tanto, o texto de Amós 7,1-6 deverá ser comentado em três seções: a primeira estudará as visões dos gafanhotos e do fogo; a segunda seção abordará o apelo do profeta Amós em favor do povo fraco e pequeno; já a terceira seção irá comentar acerca do arrependimento de Deus.

O objetivo é propor uma reflexão acerca dos principais acontecimentos elencados nas passagens de Amós 7,1-6. A problemática a ser analisada se concentra, principalmente, entre as visões entrelaçadas em conjunto (Amós 7,1-6). Essas e outras questões deverão ser agrupadas para um eventual estudo, de modo que poderão facilitar o entendimento acerca do arrependimento de Deus (e uma dessas questões pode referir-se ao apelo do profeta em favor do povo).

A metodologia usada para esta pesquisa será a pesquisa bibliográfica. Para tanto, serão usados, como referenciais teóricos, a Bíblia Hebraica Sttugartensia (tendo o texto base de Amós 7,1-6); o Léxico de Hebraico e Aramaico do Antigo Testamento, de William L. Holladay; a Bíblia Almeida Revista e Atualizada e outros.

\section{A visão dos gafanhotos e do fogo}

Nascido numa cidade do campo, Tecoa, um lugar que concentrava em seus alicerces culturais, distante das grandes cidades, uma vida simples e cultivada, Amós, que quer dizer, "aquele que ajuda a carregar o fardo", é surpreendido com as Palavras do Senhor em visão. Estas palavras vieram ao profeta dois anos antes do terremoto (Amós 1,1).

A primeira visão, de um ciclo de cinco visões ${ }^{2}$, registrada em Amós 7,1-3, relata a formação de gafanhotos ao surgir do rebento da erva serôdia, que comiam de todo a erva da terra. "Essa série de visões é um fato bastante isolado na literatura profética. Não há traços de uma tradição mais antiga de que dependesse o conteúdo das visões de Amós, como é o caso para

\footnotetext{
1 Embora seja importante estudar o ciclo das cinco visões de Amós 7, este artigo escolheu analisar apenas o primeiro par de visões: a visão dos gafanhotos e do fogo. Esta escolha partiu do critério de contextos, uma vez que o primeiro par de visões retrata o contexto agricultura.

2 Não há por que fazer um estudo historiográfico acerca das visões de Amós, uma vez que elas não oferecem esta possibilidade.
} 
as de Isaías e Ezequiel" (von RAD, 2006, p.562). "A visão dos gafanhotos cabe no início do ano agrícola" (SCHWANTES, 2004, p.38). Focaliza a vida no campo. Trata de planta e de herança, ou roça, do lavrador e também do pastor. É a vida do camponês que está em jogo.

Nisto Amós vê a praga de gafanhotos (Amós 7,1-3) e a seca $(7,4-6)$. Os gafanhotos ameaçam liquidar a herança do trabalhador da terra. Segundo esta visão, haverá fome, caso isso aconteça. E além da praga, está a caminho uma seca terrível.

Antes da aparição das visões, Amós vivia entre os pastores de Tecoa (Amós 1,1). A sua realidade era marcada por violência (cf. Amós 3,9-10): o camponês era extorquido por ricos fazendeiros. É daí que Amós tem a experiência de ver e compreender a sua realidade. Essa realidade pode ser muito bem entendida a partir das representações, ou visões, que aparecem para o profeta. ${ }^{3}$

Essa era a praga de gafanhotos, o juízo de Deus sobre Israel. Esse era o juízo fatal (PRADO, 1987, p.36-40 e 127). Juízo que virá por causa dos pobres que são oprimidos pelos mais ricos. $\mathrm{Na}$ hora de haver uma negociação entre o fazendeiro e o camponês, sempre o que compra a colheita quer sair ganhando mais. Então, o resultado é sempre o aumento do empobrecimento (SCHWANTES, 2004, p.26).

Segundo Schwantes, havia em Israel (do Norte) formas de dominações radicalizadas e outras mais agregadas. Mulheres e crianças eram dominadas, e mulheres eram violentadas coletivamente (cf. Amós 2,7) (SCHWANTES, 2004, p.28).

Schwantes vai dizer, ainda, que o ciclo de visões em Amós 7-9 só pode ser entendido em conjunto. Ele é pertinente também à pessoa de Amós e a seu meio ambiente social (SCHWANTES, 2004, p.39).

Será apenas no segundo par de visões que desemboca na palavra de Deus (Amós 8,2b): "Chegou o fim para o meu povo de Israel". Nada é esclarecido sobre o juízo num primeiro momento. Amós irá falar sobre um suposto terremoto $(2,13 ; 9,1)$, provavelmente uma guerra que Deus conduzirá contra Israel, através de um povo estranho (Amós 6,14) (SCHMIDT, 2004, p.191).

Schmidt vai dizer que a concepção profética, no sentido escatológico, em Amós 7,8 e 8,2, sugere "um fato já consumado" (SCHMIDT, 2004, p.191). Para ele, "na medida em que o futuro anunciado já condiciona o presente,

\footnotetext{
A criatividade do autor, ao representar o rico como sendo o gafanhoto, que devora toda a herança da terra, facilita a compreensão do texto. Isto pode ser visto através do perfil diacrônico do texto (ver "Amós, profeta do juízo e justiça”, REIMER, 2000).
} 
a mensagem profética merece ser chamada de 'escatológica' (apesar da controvérsia em torno do termo)" (SCHMIDT, 2004, p.191).

A ideia de um juízo catastrófico, trazido por uma nação estranha, se baseia em passagens que explicam o dia de Javé. São justamente nelas que Schmidt busca fundamentar os seus pensamentos (Amós 5,18s):

Ai de vós que desejais o Dia do SENHOR! Para que desejais vós o Dia do SENHOR? É dia de trevas e não de luz. Como se um homem fugisse de diante do leão, e se encontrasse com ele o urso; ou como se, entrando em casa, encostando a mão à parede, fosse mordido de uma cobra. Não será, pois, o Dia do SENHOR trevas e não luz? Não será completa escuridão, sem nenhuma claridade? (SCHMIDT, ${ }^{2004}$, p.192).

Para outros autores, este conflito poderá ser chamado também de o dia de Javé. Como, por exemplo, Robert H. Charles (CHARLES, 1913, p. 85-86) e John M. P. Smith (SMITH, 1901, p. 503-533), que defendem que o dia de Javé será um dia em que Javé virá em favor do seu povo nas batalhas e prosperarão Israel e Judá com glórias. Ou seja, será o dia em que não haverá mais fome e peste por causa de derrotas na guerra.

Mas há quem diga que o dia de Javé será desfavorável para o povo da terra. A. Joseph Everson (EVERSON, 1974, p.91-92), por exemplo, relaciona em seu contexto histórico cinco passagens bíblicas que tratam do dia de Javé, como sendo um dia difícil para o povo. São elas: Isaías 22,1-14; Jeremias 46,212; Ezequiel 13,1-9; Lamentações 1,12; Lamentações 2,1 e Sofonias 1,7-18.

Já o profeta Sofonias denuncia a opressão imposta pelos estrangeiros, pelos oficiais, a exploração dos mais ricos de Judá (príncipes e juízes de Jerusalém) e a manipulação religiosa imposta pelos sacerdotes e profetas (Sofonias 1,8; 3,3-4). São denúncias contra as lideranças, contra os seus abusos de poder, negligências de cargo e ostentação (Sofonias 1,12-13). Isto são acontecimentos que, em Sofonias, explicam o agir de Deus na história e entre os humanos. E isto está atrelado ao tema principal da mensagem de Sofonias: o dia de Javé.

Neste dia de terror para Israel, a proteção será tirada da cidade (Isaías 22,8) e brechas nos seus muros serão muitas (v.9). E ainda, esta maldade divina (que aparece no v.13) não será perdoada até que todos que a praticam estejam mortos.

Este dia de Javé, como dia cheio de maldade, na perspectiva de Everson, não será visto cair somente sobre a cidade de Jerusalém (ou de Israel do Norte). Isto será visto cair também sobre as cidades vizinhas (ou cidades adversárias de Israel e Judá) (Jeremias 46,1). Como, por exemplo, o Egito, que também será sentenciado pelo dia violento de Javé (Jeremias 46,1-12). 
Von Rad vai dizer que este dia de Javé, conforme Isaías 13, se trata de um conflito bélico (von RAD, 2006, p.553). Ele diz que o próprio Javé vem combater, as estrelas acabam escurecendo, a terra treme e a chacina fica terrível. Nisto, ele ainda vai dizer que Isaías 13 se trata de um poema, quando o texto encerra indicando que o império babilônico estará totalmente desolado.

Esta ideia de Von Rad é a mais aceitável, pois, de acordo com Isaías 13, o poema começa com o Senhor dando ordens aos indivíduos recrutados e terminando com a descrição do império colossal arrasado. Será a Babilônia, joia dos reinos, glória e orgulho dos caldeus, destruída como foram Sodoma e Gomorra.

Em Amós 7,2, aparece a pergunta: "SENHOR Deus, perdoa, rogo-te; como subsistirá Jacó? Pois ele é pequeno”. E no versículo seguinte (v.3), a expressão surge como que uma reação de Deus à pergunta humana (ou será intercessão?): “Então, o SENHOR se arrependeu disso. Não acontecerá, disse o SENHOR".

\section{Apelo em favor de um povo fraco e pequeno}

Vale lembrar que a segunda visão de Amós trata do fogo que consome a terra e as fontes de água. ${ }^{4}$ Diante desta, a intercessão de Amós usa o mesmo argumento que na primeira visão: Jacó é muito pequeno, frágil e vulnerável. Deus se compadece e volta atrás do juízo, que, com fogo, consumiria o grande abismo e devoraria a herança da terra. Então, Ele ouviu a intercessão do profeta Amós e se arrependeu (Amós 7,4-6).

Amós 7,3-6 mostra um Deus compassivo discursando com o profeta. Para Hubbard: "Teologicamente, portanto, o arrependimento divino é uma expressão de Sua compaixão, de Sua dedicação à aliança e de sua liberdade" (HUBBARD, 1996, p.233). Em Amós 7.3-6, conforme afirma Hubbard, o arrependimento é expresso como uma ação dedicada e compassiva de Deus. Só que Ele não perdoa, apenas cede à intercessão do profeta, anulando o castigo previsto na visão (PAUL, 1991, p.233).

Amós aparece, aqui, como alguém que se preocupa com a causa do pobre. E é nos campos, nas cidades, em frente aos reis e príncipes, em todo tempo e lugar, que o profeta defende as questões mais básicas do pobre, como a família, o plantio e a colheita. É justamente disso que trata o dito profético de Amós 6,4-6, que revela a discrepância entre ricos e pobres (RIBEIRO, 1996, p.34).

No contexto de Amós, o pobre é subornado pelo dono da prata. Dentro das cidades (Samaria), nas suas ruas e vielas, nos seus becos, há opressão por

Esta é outra representação do juízo de Deus. 
todos os lados. Os ricos (citadinos) não fazem o que é reto. Eles entesouram nos seus palácios o que arrecadam do suborno (Amós 3,9-10; 4,1; 5,11).

Às custas dos mais pobres, os ricos acumulam suas riquezas ainda mais. Segundo Schwantes, "a abastança da gente fina vem do esmagamento dos 'fracos' e desdentados, dos 'pobres' e doentes" (SCHWANTES, 2004, p.92). Esses pobres são a fonte das riquezas citadinas.

Esses lavradores empobrecidos estão numa situação grave. Amós 8,4-6, relata a ganância contra os necessitados e os miseráveis da terra. É a denúncia contra os ricos e vendedores de cereais (pequenos comerciantes) que vendem aos clientes pobres, os cereais e trigo a um preço absurdo.

Contra isto, Amós não se cala! É o anúncio do profeta Amós de que as contradições existentes no povo de Israel redundariam no fim do sistema econômico e político vigente, por causa da grande injustiça social. Esta injustiça social, segundo Ribeiro, poderia ser destruída pelo poder incontrolável de Deus, assim como a nuvem de gafanhotos destruiria a verde plantação, ou como o fogo secaria todas as vertentes (RIBEIRO, 1987, p.34). E é justamente aí, frente a esta realidade catastrófica, que a palavra profética toma as rédeas e se torna solidária, transformando-se em oração de intercessão: "SENHOR Deus, perdoa, rogo-te; como subsistirá Jacó? Pois ele é pequeno" (Amós 7,2).

Palavras como selach, que quer dizer perdoar (HOLLADAY, 2010, p.364); e chadal, que quer dizer terminar (HOLLADAY, 2010, p.136), são os equivalentes linguísticos exatos para a passagem de Amós 7,3-6, indicando um apelo humano à soberania de Deus. São expressões que aparecem antes da seguinte frase: "como subsistirá Jacó? Pois ele é pequeno" (vv.2 e 5).

Amós entende que o povo não terá todas as chances, por isso ele busca apelar unicamente a Deus. Javé jura por si mesmo, propõe abandonar o seu povo (Amós 6,8). Por três transgressões de Judá e por quatro, Javé não susta o castigo, porque rejeitaram a sua lei e os seus estatutos (Amós 2,4). E por três transgressões e por quatro, Javé também não susta o castigo de sobre Israel do Norte, porque os juízes venderam e desvirtuaram a justiça (Amós 2,6).

O profeta faz um apelo em desespero, pede perdão, e Deus se arrepende. É o humano em desespero por causa do outro que sofre, do povo fraco e pequeno. E a causa desse desespero intercessor é a dor do outro, do fraco, pois ele entende que o povo não tem todas as chances. Por isso, Amós resolve apelar à Javé desde a sua experiência como homem que sofre.

Para Amós, o dia de Javé será como um dia de trevas. Ele sugere que o povo não deseje este dia de escuridão, pois quem os salvará deste dia sem nenhuma claridade? Qual motivo fará com que Javé volte atrás deste dia tão violento? 
Mas é justamente a intercessão do profeta o motivo principal para que o nacham de Deus se torne possível? Sem esta intercessão, nada impedirá que Deus faça o seu julgamento (SIMIAN-YOFRE, 1998, p.345). Mas, será que é só isso?

$\mathrm{Na}$ primeira e na segunda visão, claro que o profeta conhece a possibilidade da preeminência de Israel antes do julgamento divino. Mas, na terceira e quarta visões, ele deve ter aprendido que Israel já não pode mais ser poupado (Amós 7,7). Conforme Jeremias, Amós ouve um "não" de Javé: "O fim veio para o meu povo Israel" (Amós 8,2). "Ao mesmo tempo, a intercessão profética deve ser silenciada em face de uma resolução divina fixa, e o arrependimento de Yahweh não pode ser falado em contradição com as primeiras visões" (JEREMIAS, 1975, p.42) $)^{5}$.

Nas primeiras visões (a visão dos gafanhotos e do fogo), Amós tem a intenção, como profeta que sofre, de explicar a misericórdia de Deus através da expressão "arrependimento", mesmo sabendo que o juízo será irrevogável (Amós 7,3-6). É o arrependimento de Deus que sugere compaixão para com os fracos.

Em Amós, entre o anúncio do juízo de Deus e o seu arrependimento, surge uma intercessão profética. Um caso semelhante a este pode ser visto em Êxodo 32,10-14, onde Moisés intercede pelo seu povo. Para este caso, Simian-Yofre vai dizer que Moisés apaziguou o semblante de Yahweh (SIMIAN-YOFRE, 1998, p.345).

Que motivo levou Amós a interceder pelo seu povo? Assim como Moisés, Amós teria apaziguado o semblante de Javé? O que levou Deus a se arrepender neste último caso? Sabe-se que o motivo para o pedido de Amós foi a fragilidade e vulnerabilidade de Israel diante da praga de gafanhotos, de como seria um terror ter que ver o seu povo sofrer com tal catástrofe. Antes disto, afinal, Amós apela para a compaixão de Deus em favor de um povo debilitado. Prado comenta que o profeta Amós reconhece que Yahweh é Deus dos debilitados e humildes: "Ele fez de nós o primeiro de todos os povos. Deu poder e glória a nossos reis, e não se esquece dos humildes que o procuram em suas aflições" (PRADO, 1987, p.8). Isso quer dizer que Yabweh não esqueceu dos pobres.

Zugleich muß angesichts des feststehenden göttlichen Entschlusses die prophetische Fürbitte verstummen, und von einer Reue Jahwes kann im Gegensatz zu den ersten Visionen keine Rede mehr sein. 


\section{O arrependimento de Deus}

O verbo arrepender-se aparece duas vezes no texto de Amós 7: na primeira vez, aparece no versículo 3; na segunda, no versículo 6. Ambas representam ações de Deus em favor do humano. É o Deus de amor que se preocupa com o fraco quando ele está em perigo. É Deus que, diligentemente, aparece para salvar o humano.

O verbo nacham aparece duas vezes na terceira pessoa do masculino singular, no perfeito nif'al. O sujeito da ação é Deus. Quanto ao objeto, ele não aparece de forma clara na passagem de Amós 7,3-6; ele só vai aparecer em Amós 6,14. Ou seja, a destruição do povo através de um exército inimigo opressor. O objeto reaparece nos relatos das visões no pronome demonstrativo zot.

Essas ações de Deus em arrependimento podem ser vistas também em outras passagens do Primeiro Testamento (Êxodo 32,12; Jeremias 26,13; Joel 2,14; Jonas 3,9). Consistem em possibilidades de Deus se arrepender como algo imaginado por humanos.

Em Exxodo 32,12, aparece o arrependimento de Deus num contexto de juízo, quando o povo consegue manchar o primeiro mandamento da lei mosaica, que é amar a Deus sobre todas as coisas. Semelhantemente ao texto de Exxodo 32,12, o arrependimento de Deus aparece, também, em Jeremias 26,13, num contexto de juízo. Jeremias 26 trata das consequências do discurso do profeta Jeremias contra o templo. Aponta para o fato de que o profeta anuncia a destruição do templo e da região não por sua própria vontade, mas como porta voz de Javé (Jeremias 26,3; Jeremias 26,13).

Já o texto de Joel 2,14 vai abordar o arrependimento de Deus num contexto de misericórdia. A volta do povo a Deus será correspondida pela volta de Deus ao povo. Esta ação de Deus pode estar voltada para o juízo (Joel 2,12). Mas, antes disto acontecer, o profeta solicita a participação de todos numa grande manifestação de penitência e jejum para suplicar a Deus o afastamento da catástrofe.

Jonas 3,9 expressa uma esperança (“quem sabe?”). Para o autor do livro de Jonas, também as nações gentias podem ser objeto da misericórdia divina. É o arrependimento de Deus num contexto de juízo (juízo que talvez poderá acontecer). É o juízo conectado à conversão humana como condição imposta por Deus.

Voltando ao texto em foco, Amós 7,1-6, o mesmo vai mostrar 0 arrependimento de Deus como possibilidade imaginada pelo ser humano. É a possibilidade como esperança, que decorre da fé em algo que ainda não aconteceu, mas que pode ser impedido. "É a imaginação de Amós que acredita que Deus pode voltar atrás em sua decisão de destruir". 
A manifestação das duas visões, a dos gafanhotos e do fogo, consiste, provavelmente, de uma epifania. Ou seja, se trata da manifestação ou revelação de Javé ao humano (FERREIRA, 2010). É certo que a aparição não se trata diretamente de Deus, mas, Ele, Deus, faz com que o profeta a veja (Amós 7,1).

Fazendo esta análise, percebe-se que a estrutura literária deste texto é usada em várias passagens quando Deus resolve chamar alguém e enviar para uma determinada tarefa. De semelhante modo, ela aparece em Êxodo 3,1-6, quando Deus chama Moisés; em Juízes 6,1-24, quando do chamado de Gideão; de Jeremias (Jeremias 1,4-10); e de Isaías (Isaías 6,1-13).

Quando a visão de gafanhotos e do fogo se mostra para Amós, o profeta logo tende a acreditar que haverá uma verdadeira chance de Deus se arrepender. É claro que, por se tratar de algo que ainda não aconteceu, esta crença humana é entendida como uma imaginação humana.

Num contexto bíblico mais amplo, o pedido humano em favor do pobre e do necessitado aparece em diversas passagens (cf. Êxodo 32,12; Jeremias 26,13; Joel 2,14; Jonas 3.9). O primeiro caso aparece registrado em Exxodo 32,11, o qual mostra Moisés intercedendo pelo povo hebreu, após Deus prometer derramar a sua ira: "Porém, Moisés suplicou ao SENHOR, seu Deus, e disse: Por que se acende, SENHOR, a tua ira contra o teu povo, que tiraste da terra do Egito com grande fortaleza e poderosa mão?”. Outro exemplo de arrependimento divino como possibilidade imaginada por humanos está em Jeremias 26,13: "Agora, pois, emendai os vossos caminhos e as vossas ações e ouvi a voz do SENHOR, vosso Deus; então, se arrependerá o SENHOR do mal que falou contra vós”. E, ainda, em Joel 2,14 e Jonas 3,9. Este último caso consiste no arrependimento de Deus imaginado por um povo gentio, a saber, Nínive (“Quem sabe se voltará Deus, e se arrependerá, e se apartará do furor da sua ira, de sorte que não pereceremos?").

Os dois últimos textos, Joel 2,14 e Jonas 3,9, sugerem a possibilidade de perdão na frase mi-yodea (SIMIAN-YOFRE, 1998, p.345). O contexto, no caso de Joel 2,14, é um apelo à penitência e arrependimento diante da iminência do dia de Javé. É o entendimento que Joel expressa de forma similar, que Deus não seria o Deus de ira para sempre, mas de misericórdia. É uma possibilidade imaginada pelo profeta (v.14). Portanto, esta expressão mi-yodea, que dizer "quem sabe" ou "talvez", é o equivalente linguístico exato para as passagens de Joel 2,14, Jonas 3,9 e Jonas 4,2, indicando um apelo imaginário à soberania de Deus.

Aqui, nacham designa uma mudança de mente ou de conduta de Deus. Não se vislumbra uma mudança do comportamento humano. Não se fala em arrependimento do povo. Deus simplesmente se compadece por causa 
da fragilidade do povo (JEREMIAS, 1975, p.41). Foi a misericórdia divina em favor do povo.

E apesar de haver, em Amós 7,3-6, a ocorrência de nacham explicando Deus se arrependendo, o seu contexto revela isto apenas como uma possibilidade, como algo que ainda não aconteceu. É apenas uma visão que retrata o futuro. Por isto mesmo, apesar de Amós 7,3 (e v.6) explicar 0 arrependimento de Deus na sua estrutura literal, este artigo, quando faz uma leitura bíblica mais ampla, parte do pressuposto de que Deus não se arrepende, ou não se arrependeu ainda (Amós 6-8). Ou, em outras palavras, o arrependimento de Deus foi apenas uma sensação humana, uma emoção de achar que viu algo.

"O arrependimento de Yahweh deve ser determinado por Amós como a mais extrema possibilidade de Yabweh de poupar os seus culpados" (JEREMIAS, 1975, p.43). ${ }^{6}$ Se Israel ainda está vivo, quando as visões do gafanhoto e do fogo se mostram, é somente pela misericórdia de Deus. Pois o estágio inicial da destruição de Israel já aparece em Amós 8,2, um capítulo após a aparição das visões: "E perguntou: Que vês, Amós? E eu respondi: Um cesto de frutos de verão. Então, o SENHOR me disse: Chegou o fim para o meu povo de Israel; e jamais passarei por ele".

\section{Considerações finais}

Além do que já fora enunciado, a postura aparentemente correta de Deus, no entanto, pode ser atravessada por sua misericórdia. Deus pode exercer autocontrole sobre a sua raiva e deixar de fazer ou deixar de pensar em fazer alguma maldade sobre a humanidade. Este exemplo poder ser visto nas duas primeiras visões de Amós 7,3-5, onde, pelo apelo do profeta, Deus se arrepende do juízo que traria (o dia de Javé) por misericórdia.

Conforme a tendência do Primeiro Testamento, no aspecto da salvação, e que acaba sendo dominante, sempre está em Deus, nunca numa condição humana (Isaías 43,25): "Eu, eu mesmo, sou o que apago as tuas transgressões por amor de mim e dos teus pecados não me lembro".

\section{Referências bibliográficas}

CHARLES, Robert H. A critical history of the doctrine of a future life in Israel, in judaism, and in christianity. London: University Press, 1913.

ELLIGER, Karl; RUDOLPH, Wilhelm (eds.). Biblia Hebraica Stuttgartensia. 5. ed. Stuttgart: Deutsche Bibelgesellschaft, 1997.

- Die Reue Jahwes ist für Amos damit zu bestimmen als die äußerste Möglichkeit Jabwes, sein schuldiges Volk zu verschonen. 
EVERSON, A. Joseph. The Days of Yahweh. Journal of Biblical Literature, Montana, vol. 93, 1974.

FERRERIA, Aurélio Buarque de Holanda. Mini Aurélio: o dicionário da língua portuguesa. 8. ed. Curitiba: Positivo, 2010.

HOLLADAY, William L. Léxico de hebraico e aramaico do Antigo Testamento. São Paulo: Vida Nova, 2010.

HUBBARD, David Allan. Joel e Amós: introdução e comentário. São Paulo: Vida Nova, 1996.

JEREMIAS, Jörg. Die reue Gottes: aspekte alttestamentlicher Gottesvorstellung. Neukirchen-Vluyn: Neukirchener Verlag, 1975.

PAUL, S. M.; CROSS, F. M. Amos: a commentary on the book of Amos. Minneapolis, MN: Fortress Press, 1991.

PRADO, José Luiz G. do. O pastor de Técua: vida do profeta Amós. São Paulo: Paulinas, 1987.

VON RAD, Gerhard. Teologia do Antigo Testamento. 2. ed. totalmente revisada. São Paulo: ASTE; Targumim, 2006.

REIMER, Haroldo. Amós, profeta do juízo e justiça. Revista de Interpretação Bíblica Latino-americana, Petropólis; São Leopoldo, vol. 35/36, p. 171-190, 2000.

RIBEIRO, Francisco Souza. Justiça: entrevista com o profeta Amós. São Paulo: Paulinas, 1996.

SCHMIDT, Werner H. Introdução ao Antigo Testamento. 3 ed. São Leopoldo: Sinodal, 2004.

SCHWANTES, Milton. A terra não pode suportar suas palavras (Amós 7,10): reflexão e estudo sobre Amós. São Paulo: Paulinas, 2004.

SMITH, John M. P. The Day of Yahweh. The American Journal of Theology, Chicago, vol. 5, n. 3, p. 503-533, 1901.

SIMIAN-YOFRE, Horacio. Theological dictionary of the Old Testament. Grand Rapids: Mermans, 1998.

Submetido em: 25-9-2017

Aceito em: 1-12-2017 